\title{
Making a Difference: A Qualitative Study on Care and Priority Setting in Health Care
}

\author{
Helge Skirbekk • Per Nortvedt
}

Published online: 25 November 2010

(C) The Author(s) 2010. This article is published with open access at Springerlink.com

\begin{abstract}
The focus of the study is the conflict between care and concern for particular patients, versus considerations that take impartial considerations of justice to be central to moral deliberations. To examine these questions we have conducted qualitative interviews with health professionals in Norwegian hospitals. We found a value norm that implicitly seemed to overrule all others, the norm of 'making a difference for the patients'. We will examine what such a statement implies, aiming to shed some light over moral dilemmas interwoven in bedside rationing.
\end{abstract}

Keywords Ethics of care $\cdot$ Professional norms $\cdot$ Value norms $\cdot$ Health professionals · Qualitative · Interviews

\section{Background}

This paper will present and discuss results from our study called "Mapping a Normative Terrain of an Ethics of Care". The study integrates philosophical and empirical analyses concerning the normative dimensions of relational care in health care prioritisations.

The theoretical background for the empirical study generates from a particular perspective in modern modern moral philosophy that is named an Ethics of Care [6, 14, 19, 20]. The dominant normative challenge that follows from this ethical perspective according to our view is that the positions defends some kind of partiality and favouritism, based on relational closeness and attachments to particular persons [12, 15]. Moreover, this seems to raise a question which is particularly important to a clinical ethics in health care, namely; how can care for 
particular and actual patients have priority, compared to the needs of patients that are not relationally (also in a temporal and spatial sense) close to the health care personell, i.e. patients on waiting lists, incoming patients etc.?

Such a conflict between care for particular persons and impartial concern for remote others have been central to moral philosophy from antiquity, and it is important to contemporary moral philosophy as well as practical and professional ethics in general $[2,10]$. To investigate ethical considerations which are salient to this tension between partiality and impartiality within a professional setting of clinical health care, we have interviewed nurses and doctors in various institutional settings of health care.

Let us give a brief introduction to the ethical problem by introducing some current empirical work pertaining to the Norwegian context. Recent studies into health care prioritisation among elderly in Norway indicate that individual and relational aspects of care are under severe strain in contemporary health care [11, 13]. E.g., lack of adequate attention to important needs for old patients is documented: Admissions to nursing homes is restricted due to scarcity, adequate time for communication with patients and relatives is lacking, proper physiotherapy and time for physical activity, and basic nursing care, such as qualified wound and nutritional care, are often scarce [13]. Hence, there are clear empirical evidence showing that the quality of individual care for elder patients may be jeopardized. Moreover, lack of relational medical and nursing care may result in increased suffering for the patient.

We ask how the tension between particularised care and impartial distributivist concerns of justice is bridged in health care settings. The doctors and nurses we interviewed were all aiming to do the best for their patients, indicating that their values and concerns of individual care are held in high regard. The documented shortage of relational care is not likely to be the result of evil or illegitimate purposes from staff or political/administrative authorities. We rather believe it follows from other sources, perhaps institutional norms or professional values stemming from an increased drive to make health care cost-efficient.

\section{Methods}

Our methods were qualitative and consisted of in-depth interviews and focus groups with doctors and nurses in Norwegian hospitals and general practices. We asked them about their priorities when caring for particular patients and what they considered to be limitations to such care within their professional work. Interviewees were in advance informed about the purpose and design of the study in both verbal and written form.

We wanted a varied population in our study, and aimed for varied backgrounds among the interviewees. 21 individual interviews have been conducted. Length of job experiences among the interviewees varied between 1 and 35 years, mean 11 years. Age varied between 24 and 61 years, mean 38 years. In three internal medicine wards in a hospital run by a Christian deaconess foundation in Oslo, we interviewed six physicians ( 3 men, 3 women) and seven nurses ( 3 men, 4 women). The first author also interviewed three nurses ( 1 man, 2 women) and two medical 
doctors (1 man, 1 woman) in an emergency ward in a hospital outside Oslo. Further, he conducted interviews with three general practitioners ( 2 men, 1 woman) in and around Oslo. Three focus groups were conducted after we had finished the interviews. These were conducted to validate our findings through triangulation [3].

Most interviewees were recruited after being informed of the study by the medical doctor heading the department or the nurse in charge of the ward, but some were recruited by the first author directly. Interviews were conducted in vacant hospital offices using a voice recorder and a notebook. Interviews were transcribed before analysis.

All interviews followed an interview guide, but they were conducted to allow for discussion and reflection upon phenomena that were of common interest. Following the approach known as active interviewing, the participants in the interviews were considered to be part of a common process of meaning-making [5, 8, 17]. This meant that both the informant and the interviewer were considered to be epistemologically active. The nurses and physicians were encouraged to reflect upon, assert their own opinions and tell their own stories concerning the phenomena discussed. Thus the interviewees were more than just conveyors of answers.

The respondents were asked about what they considered just treatment and just priorities, how they set priorities in their clinical work, how they dealt with conflicting priorities among patients with equally relevant claims to care, if such priorities were discussed openly among colleagues, expectations from colleagues and executives, and their sense of responsibility for their patients. An important question was what the doctors and nurses took to be the most salient ethical consideration (value) in their care for patients when they had to prioritise.

During analysis we looked for descriptions and explanations to explain phenomena that were relevant for our question regarding the tension between particular and impartial care. Both theoretical perspectives pertaining to issues of partiality and impartiality, and clinically oriented situations and concrete prioritisations made by doctors and nurses as a part of their care, were analysed.

Analysis was done continuously with new interviews supplementing our sample, but in general, analysis followed these stages. (1) Reading interview notes and listening to interviews to obtain overall impression. Abbreviated versions of field notes were discussed among co-authors for comments and control. (2) Noting patterns in doctors' and patients' descriptions of priority settings. (3) Whenever interpretations reached a level where hypotheses could be formed, remaining interviews were reviewed in order to find opposing interpretations [16]. (4) Based on the empirical analysis and through readings on ethics of care, a conceptual framework was developed.

\section{Results}

In this chapter we will present themes that were discussed among the health professionals we interviewed. We will particularly focus on a female consultant (experienced medical doctor) who expressed views on professional norms that we found to be rather representative. The question of reasonable spending of time with 
each patient will be examined as this was given emphasis by many health professionals. We will also look at how the professional thinking of medicine and nursing affects priority settings for the chronically ill and the elderly.

In both the acute and the internal medicine wards, several nurses indicated that they rarely discussed prioritisations at work. They sometimes discussed the time available for patient care and the efficiency of their procedures, but few said that questions regarding prioritisations among or between the patients they had to care for were being asked or discussed openly. A female physician said that most medical decisions in the hospital were based on non-verbalised values. This was later confirmed by other doctors and nurses, and as we shall see, these professional norms were rapidly transferred to younger health professionals.

Among the physicians in the internal medicine wards, discussions were said to be quite frequent, but they rarely disagreed for long periods of time. Both residents (inexperienced doctors) and consultants indicated that this was sometimes due to residents' not daring to stand up to consultants, but members of both groups claimed they quickly came to an agreement of what was the medically sound decision. Interestingly, directions from hospital management were not mentioned as very important by the doctors, only by the nurses. More than one of the consultants said their experience gave them authority to refuse to follow hospital executive guidelines if they through medical judgement considered them wrong. Hence, at least among medical doctors there was a strong sense of guarding the health related interests of the particular patients, when this conflicted with more impartial concerns salient to the hospital management. And the value underlying this kind of patientcentredness was tied to the healthrelated needs of the patient, not the patient's personal or social background.

Many nurses and almost all the doctors referred to their own choices and prioritisations not so much as prioritisations, but as 'medically sound decision making'. A nurse in the acute medical ward said it like this: "We are forced to think professionally-even if it is very unpleasant [to give low priority to patients]". The staff's care for the patients were thus impartial in one individualised sense, in the sense of concentrating on medical and health related needs, and not on the client's more personal or private preferences. Still the principle orientation of their care and priorities was partial in the way sense of guarding the interests of their particular patients in the particular situations, against administrative decisions that were grouprelated and impartial. This view was most clearly voiced among medical doctors working in hospitals, so in this paper we will focus mostly on their views.

An experienced female consultant in an internal medicine ward expressed her views in a way that both seemed meaningful and representative to many of the doctors. We will use her quotes extensively in this paper. She described prioritisations to be a 'continuing struggle to do the right thing'. There were always scans to be examined, paperwork, conversations with relatives and discussions with colleagues to be done. She said it was not necessarily hard labour, but she never considered herself finished with her work. And that meant she continuously had to prioritise between what to do first and what to do last. She considered this choice to be easy if her decision could make the difference between 
life or death for the patient, but harder if the options were more vague, e.g. if psychosocial settings were part of the question.

When the patient fails one, maybe two illnesses, everything will be okay. Then it is very easy, in a professional sense. The big problem is when the patient fails more, several things. ... Now [many patients have], God help me, seven [...] illnesses [...] And we are supposed to not just consider the diseases, which is what we are taught to do in the medical sciences, but we will consider them against the psychosocial setting. And some [doctors] drown themselves in the quagmire the psychosocial setting sometimes represents [laughs]. Other [doctors] get 'super-professional' and only see the heart and forget that [the patient] is living on the 5th floor without an elevator.

Psychosocial questions often meant the doctor had to discuss and negotiate with the patients. A young male general practitioner emphasised the need for such negotiations, but also the problems. Negotiations were often more necessary if the trust relation with the patient was poor. In such cases patients were often examined more than necessary:

It is a bit of negotiation, you know. 'No, you will not get more Vival, but I take your cough seriously and will send you to x-ray'. And I would not have done that with a person that I had a good trust relation with, someone that I did not need to bargain with in order to maintain a good alliance.

These difficulties of having enough time for both diagnostics and personal patient contact were mentioned by several doctors. A male registrar considered time restrictions as prioritising not only between diagnostics and time spent with patients, but also against keeping updated with relevant medical journals. Other physicians also explained that it was far more important to keep updated with medical research than to spend time with the patients.

Time's limited, so you have to prioritize between patients, but I think maybe even more to prioritize between different tasks - in a way, should I take the time to make a good journal entry or should I spend time with patients and their families? Should I [...] make a reasonably good job and save some time for things that perhaps are even more exciting, like [reading relevant literature and] professional specialization of different kinds?

The question of doing a 'good enough job' seemed relevant for many of the doctors and nurses interviewed. The female consultant posed the question like this: "Is 'just good enough' good enough? Or should all treatment always be the best?" She continued by describing the dangers of taking too much responsibility for the patients and their psychosocial settings:

One of our female consultants - a very clever, clever geriatrician-caring, good with patients - was completely exhausted - ended up burnt out and working half time [...] because she did the very best, all the time. She did diagnostics, trained assistants, talked with the interdisciplinary team, talked with the patient, she even wrote letters to the care centres that they should take 
care of the patients in the best possible way.... Well, then you simply have not done those prioritizations. Because one of the priorities - you have to be able to go home and still be a human being.

The need to emphasise 'medically professional thinking' meant doctors had to concentrate on what only they could do, even if that meant "softer" aspects of patient care often would have to be left to the nurses.

The dying man in need of care should be able to get it from someone other than me. [...] I think that doctors are a little troubled to say that ... because we [doctors] 'should all be so nice', we should be at least as 'good' as the nurses. [...] So then we start carrying pans and patting the cheeks [of the patient] and [whatever]. I pat the cheeks of my patients lots of times, but I see that we sometimes do not have enough time to do what only doctors can do, because we spend so much time patting cheeks.

This focus on medical objectivity and individual impartiality is clearly rational and legitimate, but the consequences may be unwanted. What follows from this is the view that patients with the most severe and acute needs, in a biomedical sense, should be treated first, and patients with less severe and acute needs, but perhaps more severe needs of caring, will have to wait. The norm among doctors to 'do what matters most' was used by several physicians as a reason not to spend too much time with the patients, to 'avoid polite chatter' as another physician phrased it. This meant the chronically ill were given low priority because their problems were less acute. Still, many doctors expressed regret that these patients were not given treatment quicker. Nurses were more willing to prioritise the chronically ill.

In the acute ward, we interviewed an executive medical doctor with many years of experience. He voiced what most other doctors also said: "The acutely ill must be looked for first and that means that the chronically ill will be given a low priority." He defended this way of thinking, but at the same time he saw the ethical problems this may lead to. e.g., many patients were waiting for examinations in the hallways: "It is an appropriate setting of priorities, but there is no ethical dignity attached to it. It's disgraceful to be put to bed in the hallways_-visible to everyone running around when you are in pain." His expressed solution to this problem, shared by some of the other consultants/attending physicians as well, were to offer more treatment to more patients outside the hospital:

[I]t is so important to try to treat as many as possible of the chronically ill outside the hospital. In a way - what should the chronically ill be doing in a hospital? They should to a greater extent be offered treatment elsewhere.

This clear priority of acute before chronic diseases were repeated among all the doctors and nurses interviewed in the acute ward. A modified TRIAGE system of prioritisations was in use here [9], giving colour tags to all incoming patients. 'Red' and 'orange' meant patients were attended by doctors immediately or within minutes, 'yellow' meant half an hour, and 'green' and 'blue' usually meant the patient had to wait for a very long time or was recommended to seek medical attention elsewhere. 
In the internal medicine wards, no formal system of prioritisations was in use. However, acute diseases were given priority here as well, and informal value systems were transferred to new doctors and nurses through a detailed focus on treatment. A young specialty registrar explained the rationale for this:

A patient with late stage cancer - he will die from it, so in a way he is very seriously ill - but he will not be prioritised. He will be examined to find out what sort of cancer it is. There is nothing urgent with his illness, he could easily wait a week without examination being urgent for his diagnosis [...] Someone else, just as seriously ill, but where rapid intervention actually would mean something for the patient's treatment, he would be prioritized [...] A fairly obvious way of thinking that we 'get in the blood' very quickly.

According to the interviewees in the internal medical wards, not giving priority to the chronically ill did not mean drug or alcohol addicts were given any worse treatment than other patients. They were given different treatment, because their bodies could not necessarily handle the normal treatments. Many interviewees considered addicts difficult to work with, but they were treated at the same priority setting as other patients. "We are no less committed to treating them" as a young doctor phrased it.

However, older patients were given low priority settings in all hospital wards, although for somewhat different medical reasons. The female consultant mentioned earlier stated that she did not make her greatest efforts if the patient was dying, without pain, and in need of palliative care. According to her, this was not to treat patient groups differently, but quite simply the medically sound thing to do: Partly because the risk with treating older patients was greater, partly because the patients' quality of life after treatment would not necessarily improve, partly because the kind of care the patients needed was considered the nurses' job.

Topics that could be discussed among the physicians were phrased in ways similar to 'will the patient benefit from this treatment?', 'how long will the patient live after treatment?', 'will the patient be able to live through treatment?', 'what are the patients'/relatives' wishes?', and, very rarely, 'what will it cost?' The answers to such questions in general, meant patients with medically unexplained symptoms often would have to wait. Our female consultant explained similar views in a slightly arrogant way, but still she emphasised the individual needs of her patients for both human and medical care.

A patient who is dying and without any pain - No, I will not do more than I absolutely have to do then. Instead I will go to the outpatient clinic and investigate and treat a patient for whom there is still hope, still has a life and where it means something that I make an effort [our emphasis].

\section{Discussion}

The norm "to make a difference for the patient through medically sound decisions" seemed to penetrate nearly all clinical prioritisations, at least according to the 
doctors interviewed. Here we will discuss this taken-for-granted norm and some challenges that follow from the perspective of an ethics of care.

We see that neither doctors nor nurses behaved impartially in their general clinical orientation regarding priorities. They were not particularly concerned with hospital budgets or the cost-efficiency of care, as long as the care and treatment prescribed was what the patient needed. It does seem, however, that doctors were more diagnostically orientated and focused on the medical need of the patients, while nurses, also focused on the meeting the subjective needs of the patients, giving comfort and care. It is interesting that also doctors recognized the values of such interpersonal care, but would not give it priority.

To 'hold the patient's hand' was seen by many physicians as the nurse's role, and unnecessary to fulfil the doctor's role of diagnosing correctly and prescribing correct treatment. Most doctors interviewed saw problematic effects of this view for the professional role of the doctor. Some would have wanted to spend more time with the patients, discussing their condition or spiritual needs, but all doctors saw this as less important than what they expressed as medically speaking 'making a difference for the patient'. Nurses were far more likely to prioritise patients with needs of caring, but with less severe medical needs.

Both groups of professionals, however, seemed to voice the kind of ethical particularism essential to an ethics of care, i.e. responding to the particular individual in the particular situation, rather than being motivated by abstract and universal principles. They were engaged in finding the best solution for the patient in the actual situation. Their primary responsibility almost always seemed to be the particular patient assigned to their particular care. The impartial character of this particularist orientation is best exemplified in their attitude towards justice as part of care. The health professionals in our study tried to make a difference for all the patients in their care, regardless of background, but they were treated differently according to the norms of medical treatment.

In our study we found that the deaconess hospital's Christian values were not endorsed by more than a minor majority of the health professionals interviewed, but they all professed to follow the values of the hospital. These values can be seen as being expressed through the health professionals' agreement on letting drug addicts be prioritised on a level similar to other patient groups. Also, elderly patients were thought of as being treated with the same opportunities for treatment as other patients. However, neither older patients, nor drug or alcohol addicts, are necessarily receptive to the same treatment as other patients. Elder patients not being given the same treatment as other patients on the basis of their medical condition is consistent with what has been expressed in other empirical studies [4, 13].

We found that most health professionals, especially the doctors, rarely regarded their own clinical decisions as prioritisations, but rather as medically sound decision making. Informal and implicit norms are not necessarily a problem for health professionals' decision-making, but taken-for-granted norms may become problematic if health professionals are not aware that there are alternative ways of thinking and prioritising [18]. Medical knowledge is not without implicit values. Even if health professionals are oriented to impartial priorities of patients, hidden values and norms may influence their priority settings. As an example, we will see 
how informal prestige of diseases may influence what is considered medically sound decisions.

Formal rules may say quite clearly that acute and life-threatening diseases must be prioritised, but health professionals are relatively free to interpret what kinds of diseases fall into these categories based on what they take to be relevant medical judgment in the particular case. Informal and non-verbal rules of prioritisation are therefore relevant as they may influence taken for granted priority settings. During medical training doctors and nurses learn how to make prioritisations like proper health professionals. What is considered medically sound decision making may thus be taught from the experienced health professionals as non-verbal rules of prioritisation to the inexperienced.

E.g., in the social sciences, diseases can be interpreted as the way we, as a society, think about these diseases. Sometimes this is referred to as sickness to separate it from disease (biomedical) and illness (psychological) [7]. Epileptic seizures has been interpreted as, respectively, signs of divinity and of sin, during different time periods in European culture. In Western society today, we often find the prestige of diseases are lower if the disease gives symptoms we find revolting or if the patient can be seen as the cause of his or her own disease, e.g. diseases caused by alcohol or smoking.

Prestige is very rarely part of any formal kind of prioritisation, but no organisation can prioritise strictly according to formal rules. What is implicitly thought of as prestigious may colour what health professionals consider medically sound decision making. Album and Westin [1] have researched the prestige of diseases among Norwegian medical doctors. They found that diseases associated with technologically sophisticated, immediate and invasive procedures were given high prestige scores. Further, the location of the disease in the body also mattered, with brain and thorax diseases ranking high (e.g. myocardial infarction, leukemia, brain tumour). Diseases located lower in the body, or with no particular location ranked low (e.g. anorexia, AIDS, schizophrenia, fibromyalgia). Chronic diseases with less visible results from treatment were given lower prestige scores, as were diseases associated with the elderly. Unfortunately, no similar study has been conducted among nurses.

The norm of 'making a difference for the patient' might be understood as corresponding to Album and Westin's understanding of higher prestige where clear and visible treatment results are likely. Prestige is given to an action-oriented approach based upon the most pressing needs for medical treatment. The focus of care by the doctors is on what they do and what they can do to cure the patient, and not so much on how they care for the patient. Nurses are expected to focus more on the softer side of care, and how they can make a difference for the patient in how they behave, how they inform and how they give consolation and trust to the patient. However, in our study nurses shared the view with doctors that patients should be treated according to 'who needed it most', and even they felt they did not have much time for traditional patient care. But nurses were also far more likely than doctors to lament that they did not have time enough to talk with the patients, to listen to them and their problems. The differences between nurses and physicians are thus perhaps not as big as we could have expected, at least considering the focus 
nurses have on care in their training, education and self-understanding as a profession [11].

Both doctors and nurses indicate that they try to be advocates for their patients. They try to help their patients in words (e.g. arguing for the importance of their patient's treatment) or in action. However, how this help is performed varies according to the value system of either doctor or nurse. Doctors focus on 'making a difference for those patients that medically are in most acute need of treatment. Nurses, in general, focus more on helping the patient through 'comfort and care for those that need it most', i.e. softer aspects of care. Norms for priority settings may of course be given formally by managers or politicians, but our study showed that, especially among doctors, such guidelines were not necessarily followed. One doctor referred to politicians as 'cowards' if they did not set priorities, and 'inhuman' if they did. Doctors instead seemed to follow the norm that they called 'medically sound decision making'. We have already examined some clinical effects of following this norm, but we have not yet examined how such informal value systems in theory may influence communication with patients.

According to an ethics of care a patient has a value that exceeds the particular request and need for treatment that is the reason for admittance to institutional care in the first place. Also, and even more important, an ethics of care treasure relationships between persons, and in our context, how a professional carer is able to protect and care properly for his or her patient. This kind of interpersonal care also value how one cares for the patient, creating atmosphere of trust and concern. It appears that the doctors are generally more action oriented in their care, while the nurses value softer and more emotional caring. The norm of 'making a difference' was commonly used referring to diagnostics and treatment, while caring for patients' unique otherness as persons was often seen as the nurses' task. Both doctors and nurses, however, express the value of their particular patient to give institutional room for making exceptions based upon a patient's particular vulnerability, psychological circumstances etc. This also means that in some cases, particular circumstances and vulnerabilities may represent good reasons for treating persons unequally.

The asymmetrical nature of the relationship between health care workers and patients means that care can rarely be reciprocal. Patients' particular needs, interests and desires must be given moral emphasis. E.g. a frail elderly who wants to stay in the institutions a little longer until her relatives can take care of her at home, or a drug addict not capable of taking care of himself and wants to stay in the nursing home together with carers who have known him for a long time-despite other relevant reasons for moving him to another institution. Our study revealed that both doctors and nurses frequently took such needs into account. This meant that they in effect functioned as their particular patients' advocates in opposition to impartial and institutional demands. But this was often done despite the formal instructions to take care of the acutely ill. The informal norm of 'making a difference through medically sound decisions' thus seemed to work in favour of both acute care and care of patients' particular needs, but particular needs were given lower priority if doctors did not judge further treatment as 'making a difference' for the patient. 


\section{Conclusion}

The view that prioritisations in clinical health care is understood solely on the basis of medically sound decisions seems to narrow professional ethics to what is contained in medical knowledge alone. We have indicated how treatment and diagnostic preferences are influenced by cultural and societal norms and values. Medical knowledge is certainly not devoid of values. As the doctors say themselves, medical activity contains hidden values and priorities, such as the acutely ill having priority before the chronically ill. And of course, health professionals' assessments concerning quality of life, and patients' and relatives' preferences, cannot be devoid of value and are at the same time important parts of all sound clinical judgments concerning priorities.

While competent medical treatment always will be essential in health care, more "soft" values of care may easily be undermined by the more important norm of making a difference for the patient. To care for the patient and his or her relatives as human subjects also calls for universal aspects of care, aspects that unifies professional care as integral parts of both medicine and nursing. Altogether a clearly particularistic attitude permeate both medical doctors' and nurses' attitude toward patient care. Even though nurses to a greater degree than doctors are guided in their care by the subjectivity of the patient, both seem to base their care on some kind of patient-centred partiality. Both doctors and nurses seem very conscious that no univeralist aims of health care can be attained if one's basic responsibilities to one's concrete patients is undermined.

Conflict of interest The author(s) declared no conflicts of interest with respect to the authorship and/or publication of this article.

Open Access This article is distributed under the terms of the Creative Commons Attribution Noncommercial License which permits any noncommercial use, distribution, and reproduction in any medium, provided the original author(s) and source are credited.

\section{References}

1. Album, D., \& Westin, S. (2008). Do diseases have a prestige hierarchy? A survey among physicians and medical students. Social Science and Medicine, 66, 182-188.

2. Annas, J. (1993). The morality of happiness. Oxford: Oxford University Press.

3. Denzin, N. K. (1970). Sociological methods. A sourcebook. Chicago: Aldine Publishing Company.

4. Førde, R. et al. (2006). Får eldreomsorgen nok ressurser? Tidsskrift for den norske legeforening, 126(15), 1913-1916.

5. Gubrium, J. F., \& Holstein, J. A. (1997). The new language of qualitative method. Oxford: Oxford University Press.

6. Held, V. (2006). The ethics of care. Oxford: Oxford University Press.

7. Kleinman, A. (1988). The illness narratives: Suffering, healing, and the human condition. New York: Basic Books.

8. Kvale, S. (1996). InterViews. An introduction to qualitative research interviewing. Thousand Oaks: Sage.

9. Mackway-Jones, K., \& Ryan, B. (1989). Triage labels. Choosing the national standard. BMJ, 299, 620 . 
10. Nortvedt, P. (1996). Sensitive judgment-nursing, moral philosophy and an ethics of care. Oslo: Tano Publishers.

11. Nortvedt, P. et al. (2008). Professional roles in clinical health care for the aged. Journal of Medical Ethics, 34, 332-335.

12. Nortvedt, P., et al. (2007). For gammel og syk? Prioriteringer av helsetjenester til eldre. Demens og alderspsykiatri, 11(1), 38-41.

13. Pedersen, R., et al. (2008). In quest of justice? Clinical prioritisation in health care for the aged. Journal of Medical Ethics, 34, 230-235.

14. Pettersen, T. (2008). Comprehending care-problems and possibilities in the ethics of care. Lexington: Lexington Books.

15. Scheffler, S. (2002). Relationships and responsibilities. Oxford: Oxford University Press.

16. Silverman, D. (2001). Interpreting qualitative data. Methods for analysing talk, text and interaction. Sage Publications: London.

17. Skirbekk, H. (2008). The patient's trust. Theoretical analyses of trust and a qualitative study in general practice consultations. Oslo: Faculty of Medicine, University of Oslo.

18. Skirbekk, H. (2009) Negotiated or taken-for-granted trust? Explicit and implicit interpretations of trust in a medical setting. Medicine, Health Care, and Philosophy, 12(1).

19. Slote, M. (2007). The ethics of care and empathy. New york: Routledge.

20. Tronto, J. (1993). Moral boundaries. New York: Routledge. 